\title{
Neonatal rickets
}

\section{Histopathology and quantitative bone changes}

\section{S J OPPENHEIMER AND G J A I SNODGRASS}

Department of Morbid Anatomy, London Hospital Medical College, and Department of Paediatrics, London Hospital

SUMMARY Ribs from 3 preterm infants, who had died after prolonged intravenous feeding and artificial ventilation, were examined histologically and assessed for the degree of osteomalacia and osteoporosis in cancellous bone of the shaft. A grid counting technique was used. Osteomalacia was noted in all 3 cases but to a lesser degree than in classical vitamin D-deficient controls. Osteoporosis was pronounced in the cases of neonatal rickets, but this was not a feature of the vitamin D-deficient controls. Histological features were similar to those reported in experimental phosphatedeficient rickets and vitamin D-resistant rickets.

A combination of rachitic changes and multiple rib fractures occurring in preterm infants has been described by several authors. ${ }^{1}$ This report describes the histology and quantifies the changes in cancellous bone occurring in 3 neonates dying with rickets; each had received prolonged intravenous alimentation including intravenous vitamin $\mathbf{D}$.

\section{Material and methods}

Three groups were studied.

Normal controls, 9 term fresh stillbirths and firstweek neonatal deaths.

Vitamin D-deficient rickets, 6 cases occurring in infancy were obtained from the London Hospital pathological collection.

Neonatal rickets, 3 infants who had died of bronchopulmonary fibroplasia and heart failure after prolonged mechanical ventilation. Each of them had received prolonged intravenous feeding including intravenous vitamin D supplements of 200 IU daily $(5 \mu \mathrm{g})$. In each case there had been $x$-ray and biochemical evidence of rickets before death.

Suitably-stained, undecalcified sections of rib were assessed quantitatively for osteoid and mineralised bone content. A grid area point counting method was used. ${ }^{2}$ This enables an accurate estimate to be made of the areas occupied within cancellous bone by osteoid and mineralised bone. A Zeiss integrating disc No 4 was used, which incorporates a grid of 900 points. Only cancellous bone in the shaft of the rib was studied and an average of 7 different area counts was taken for each case (that is 6300 points).

To separate elements of osteomalacia and osteoporosis, the results were expressed in the following form:

$\%$ osteoid $=$ mean osteoid grid count $\times 100 /($ mean osteoid grid count + mean mineralised grid count).

This expression indicates the proportion of the total osseous tissue that is uncalcified (normal $<5 \%$ ). ${ }^{2}$

To produce a value for the proportion of total osseous in cancellous bone (that is, bone density), the osteoid and mineralised bone counts were combined and expressed as a percentage of the total tissue area. Thus:

$\%$ total osseous tissue

$=$ (mean osteoid grid count + mean mineralised grid count) $\times 100 / 900$

The statistical method used for comparison was the Mann-Whitney U test.

\section{Results}

The relative values of $\%$ osteoid and $\%$ total osseous tissue are shown in Fig. 1. The mean \% total osseous tissue in the normal controls was $33.6 \% \pm 1.0(\mathrm{n}=9)$, while that in the vitamin D-deficient rickets cases was $37 \cdot 5 \% \mathrm{SE} \pm 2 \cdot 8$ $(n=6)$, a nonsignificant difference $(P>0.05)$. In contrast, the \% total osseous tissue in the 3 intravenously-fed infants was less than $20 \%$. This was significantly less than in both the other groups $(\mathrm{P}<0.05)$. The mean \% osteoid in the normal 


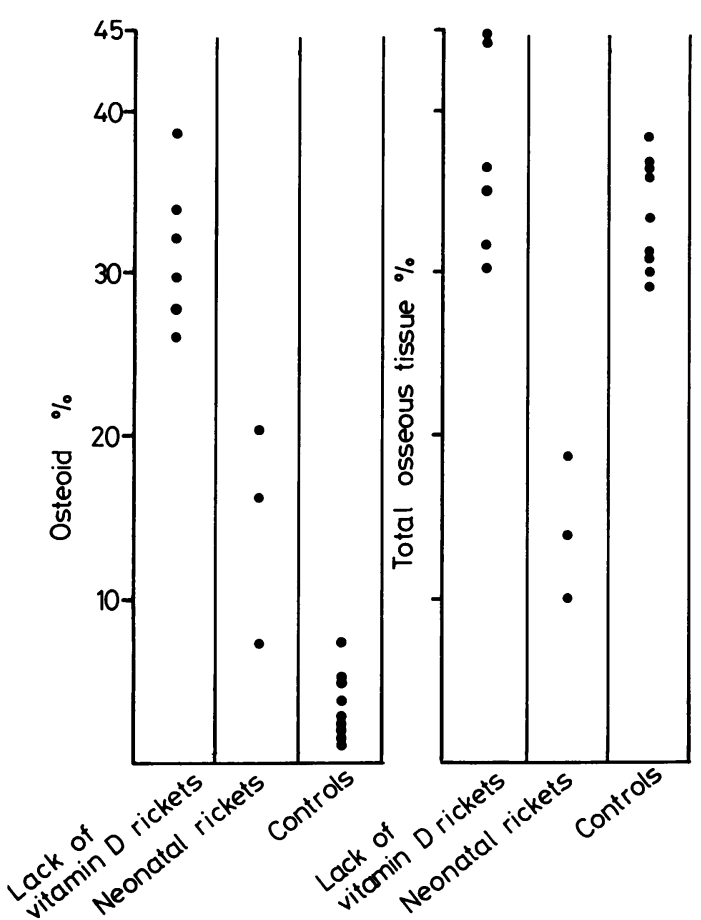

Fig. 1 Relative proportions of $\%$ osteoid and $\%$ total osseous tissue.

controls was $3.5 \% \mathrm{SE} \pm 0.7(\mathrm{n}=9)$, much less than that in vitamin $D$-deficient rickets $(P<0.001)$. As can be seen from Fig. 1, the \% osteoid in the intravenously-fed infants occupied an intermediate position between the normal infants and the classical vitamin D-deficient cases, and taken as a group were different from either of the other groups $(P<0.05)$.

\section{Histopathology}

A normal costochondral junction from a term stillbirth is shown in Fig. 2a.

\section{Vitamin D-deficient rickets.}

Ribs

All 6 cases showed classic florid changes of vitamin D-deficient rickets. The histological changes have been fully described, ${ }^{3}$ but the following are relevant to the discussion. There is gross enlargement of the costochondral junction (Fig. 2b). This is due to the expansion in thickness and lateral width of the cartilage plate and to the production of a thick band of osteoid. With osteoblastic activity normal or increased, there is deposition of abundant osteoid directly on to cartilage. Failure of osteoclastic resorption occurs since osteoclasts can only remove calcified material. As a result the cartilage is inadequately removed and there is irregular invasion of blood vessels. Subperiosteal bone formation is less affected; it overtakes endochondral ossification at the sides and produces the characteristic cup deformity (Fig 2b).

In the shaft, trabeculae are orientated in a bizarre fashion, tend to be thickened, and are covered over most of their surfaces by thick osteoid seams. Calcified bone is of the lamellar type. Osteoblastic activity is normal or increased. Osteoclastic activity is reduced or absent.

The cortex tends to be thickened and covered with a thick osteoid seam; it is often reduplicated. With the virtual absence of osteoclasts normal resorption remodelling does not occur.

\section{Neonatal cases.}

\section{Case 1}

Case 1 was fed intravenously throughout life (3 months) and by the time death occurred at the gestational age of 44 weeks, rachitic changes were florid. These are described in detail.

The ribs on the left from 7 to 10 and on the right from 6 to 10 were fractured at the angle. Around each fracture was a hard fusiform swelling $5-7 \mathrm{~mm}$ in diameter. The ribs were soft and easily deformed (as were all bones examined). The costochondral junctions were enlarged up to $6 \mathrm{~mm}$ anteroposterior. The lower femoral ossifications centre was present. Specimens of lower end of femur, rib, and rib fracture were taken and embedded undecalcified in methacrylate. Histologically (Figs $2 c$ and d), there was an enlargement of the costochondral junction to $5.5 \mathrm{~mm}$ (normal $3 \mathrm{~mm}$ ). The hypertrophic zone of cartilage was increased to $3 \mathrm{~mm}$ and the columns of hypertrophic cells showed disorderly alignment and pronounced variation in size, with many large ellipsoid lacunae especially at the periphery. The normally clear junction between the hypertrophic zone and the zone of provisional calcification was replaced by a disorganised area $3 \mathrm{~mm}$ deep, where there was irregular penetration of the cartilage by blood vessels leaving residual large tongues and islands of calcified cartilage (TCC) deep in the primary spongiosa (Figs $2 \mathrm{c}$ and d). These tongues of calcified cartilage were partly covered with thin osteoid. Also in this disorganised area were scattered small islands of osteoid. A few osteoclasts were seen in the primary spongiosa mainly associated with islands of partly calcified cartilage.

The cancellous bone of the shaft was characterised by (1) thin, sparse, irregular, poorly-calcified 
trabeculae consisting of woven bone. (2) Moderately thickened osteoid seams covering approximately half the surface of the trabeculae. (3) Very little osteoclastic activity. (4) Very few and flattened osteoblasts.
The cortex of the shaft was very thin and in one place buckled. There was a thick layer of subperiosteal osteoid on the outer cortex but poor osteoblastic activity.

The rib shaft was very porotic. There was an

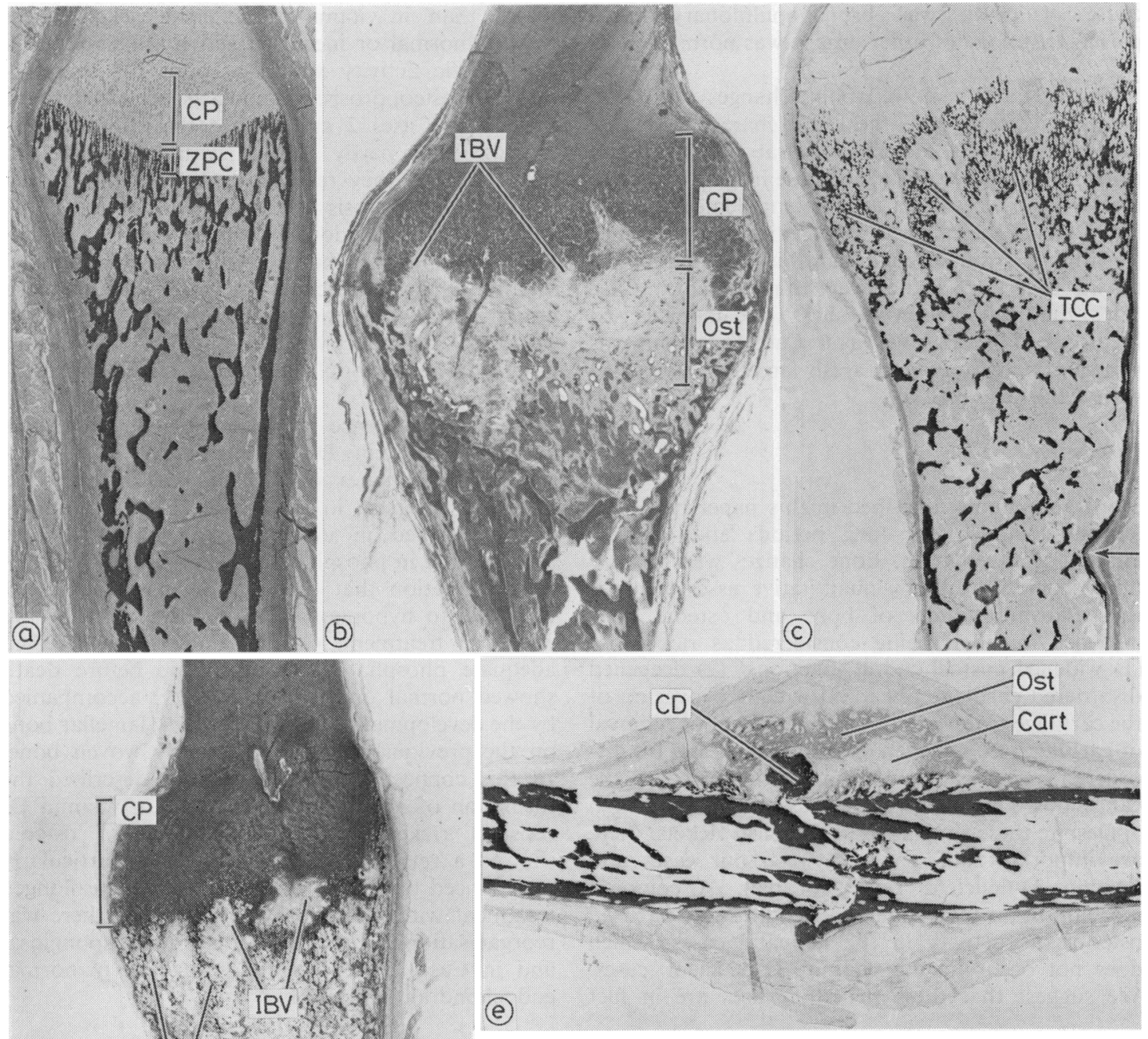

Fig. 2 Undecalcified sections of rib from (a) normal stillbirth, (b) classical vitamin D-deficient rickets, $(c)$ and $(d)$ Case 1 (neonatal rickets), (e) rib fracture from Case 1.

Fig. $2(a, c, e$,$) Von Kossa stain for calcification. Fig. 2(b, d)$ haematoxylin and eosin. $\times 12$.

$\mathbf{C P}=$ cartilage plate, $\mathbf{Z P C}=$ zone of provisional calcifaction, IBV $=$ invading blood vessels, ost $=$ osteoid, TCC $=$ tongues of calcified cartilage, $C D=$ calcified deposit, Cart $=$ cartilage 
irregular fracture but no displacement (Fig. 2e). The trabeculae adjoining the fracture site showed only slight signs of remodelling. The callus was composed of abundant osteoid and metaplastic cartilage but showed little calcification.

Lungs showed marked parenchymal fibrosis: the cause of death was bronchopulmonary fibroplasia. Histology of other organs was normal.

Cases 2 and 3 showed bony changes similar to those of Case 1, with the same characteristic disorganisation of the costochondral junctions and generalised osteoporosis, but these infants, who had received intravenous phosphate supplements in the last weeks of their lives, showed evidence of healing: (1) although the osteoid seams in the shaft were thicker than normal they were thinner than in Case 1 ; (2) the trabeculae in the shaft were characterised by a core of woven bone (as in Case 1) but this was surrounded by a layer of fresh lamellar bone lined with active osteoblasts.

\section{Discussion}

The three infants described in this paper had been fed intravenously for long periods and received vitamin D throughout. Bone changes were similar microscopically and by quantitative assessment of the relative amounts of bone and osteoid. The evidence for their being considered as rickets is: (1) widened costochondral junctions; (2) deepened disordered cartilage plate; (3) irregular invasion of the cartilage plate by blood vessels; (4) poor removal of cartilage; (5) widened osteoid seams; and (6) disordered remodelling of the cortex and of the cancellous bone of the shaft.

Despite these similarities to classical rickets, there are important differences between our cases and vitamin D-deficient rickets (Table). A common mechanism for these differences could be a decreased osteoblastic activity in the neonatal cases, which does not occur in the vitamin D-deficient cases. We suggest that these neonatal cases are in fact hypophosphataemic rickets and that this rickets is characterised by: (1) inadequate mineralisation of osteoid (as in vitamin D-deficient rickets), and (2) reduced osteoblastic activity.

The histology of Case 1 shows the osteoblasts to be fewer in number and forming considerably less matrix than in vitamin D-deficient rickets where there is normal or increased activity. This reduced osteoblastic activity would account for the pronounced osteoporosis. Osteoblasts appeared to be normal in Cases 2 and 3, but these infants had already been partly treated with phosphate; in other respects they resembled Case 1 and showed marked osteoporosis and disorganisation of the costochondral junction. In this connection osteoporosis is an established accompaniment of familial vitamin D-resistant rickets. ${ }^{4-5}$ Moreover Villanueva et al. ${ }^{6}$ obtained direct evidence of marked reduction of osteoblastic activity in vitamin D-resistant rickets using a double tetracycline labelling technique.

Another difference between the neonatal rickets cases and vitamin D-deficient rickets is the persistence of tongues of calcified cartilage in the primary spongiosa in the former. Similar findings were described in untreated vitamin D-resistant rickets, ${ }^{7}$ and in phosphate-deficient rats. ${ }^{8}$

Confirmation that the bone changes in Case 1 were due to hypophosphataemia is shown by the effects of treatment. Cases 2 and 3 who received adequate phosphate for some time before death showed normal osteoblastic activity, accompanied by the development of normal orderly lamellar bone on the previously formed disorderly woven bone. In this connection Engfeldt et al. ${ }^{9}$ described the formation of abnormal woven bone in vitamin $D$ resistant rickets. The mineralisation of osteoid showed a return to normal; this was particularly pronounced in Case 3 who had received prolonged treatment with phosphate. Furthermore, there was reorganisation of the area of the primary spongiosa, and in Case 3 the beginnings of orderly normal endochondral ossification.

Table Bone histology compared in vitamin D-deficient rickets and neonatal rickets

\begin{tabular}{|c|c|c|c|c|c|}
\hline & \multirow{2}{*}{$\begin{array}{l}\text { Normal } \\
\text { controls } \\
(n=9)\end{array}$} & \multirow{2}{*}{$\begin{array}{l}\text { Vitamin D-deficient } \\
\text { rickets } \\
(n=6)\end{array}$} & \multicolumn{3}{|c|}{ Neonatal rickets } \\
\hline & & & Case 1 & Case 2 & Case 3 \\
\hline \multicolumn{6}{|l|}{ Costochondral junction } \\
\hline $\begin{array}{l}\text { Accumulation of osteoid against cartilage plate } \\
\text { Calcified cartilage tongues in primary spongiosa } \\
\text { Rib shaft }\end{array}$ & $\begin{array}{l}\text { Absent } \\
\text { Absent }\end{array}$ & $\begin{array}{l}++ \\
\text { Absent }\end{array}$ & $\begin{array}{l}\text { Verylittle } \\
++\end{array}$ & $\begin{array}{l}\text { Very little } \\
++\end{array}$ & $\begin{array}{l}\text { Very little } \\
++\end{array}$ \\
\hline $\begin{array}{l}\text { Thickness of trabeculae } \\
\text { Thickness of osteoid seams } \\
\text { Proportion of trabeculae covered by osteoid (\%) } \\
\text { Osteoblastic activity } \\
\text { Cortical thickness }\end{array}$ & $\begin{array}{l}\text { Normal } \\
\text { Normal } \\
\text { Normal } \\
\text { Normal }\end{array}$ & $\begin{array}{l}\uparrow \\
\uparrow \uparrow \\
90 \\
\uparrow \text { or normal } \\
\uparrow\end{array}$ & $\begin{array}{l}\downarrow \downarrow \\
\uparrow \\
50 \\
\downarrow \downarrow \\
\downarrow \downarrow\end{array}$ & $\begin{array}{l}\downarrow \downarrow \\
\uparrow \\
50 \\
\text { Normal } \\
\downarrow\end{array}$ & $\begin{array}{l}\downarrow \downarrow \\
\uparrow \\
30 \\
\text { Normal } \\
\downarrow\end{array}$ \\
\hline
\end{tabular}


In conclusion, histological evidence is presented that rickets occurring in preterm infants intravenously fed is qualitatively and quantitatively different from vitamin D-deficient rickets. Phosphate deficiency may be an aetiological factor. Clinical supporting evidence for this will be presented in a subsequent paper.

We thank Professor I Doniach and Professor B Vernon-Roberts both formerly of the Department of Morbid Anatomy, London Hospital Medical College, for advice, Mr V Trenwith, Senior Technician, for preparing the undecalcified sections, and Dr E M E Poskitt, Institute of Child Health, Alder Hey Hospital, Liverpool, for reading the manuscript.

\section{References}

1 Anonymous. Rickets, jaundice, and late onset respiratory distress in premature babies. $\mathrm{Br}$ Med J 1977; ii: 78-9.

2 Woods C G, Morgan D B, Paterson C R, Gossman H H. Measurement of osteoid in bone biopsy. J Pathol Bacteriol 1968; 95: 441-7.

3 Pommer G. Untersuchungen über Osteomalacie und. Rachitis. Leipzig: Vogel, 1885.
${ }^{4}$ Cooke W T, Barclay J A, Goran A D T, Nagley L. Osteoporosis associated with low serum phosphorus and renal glycosuria. Arch Intern Med 1947; 80: 147-64.

5 Hauge B N. Vitamin D resistant osteomalacia. Acta Med Scand 1956; 153: 271-82.

6 Villanueva A R, Ilnicki L, Frost H M, Arnstein R. Measurement of the bone formation rate in a case of familial hypophosphatemic vitamin D resistant rickets. J Lab Clin Med 1966; 67: 973-82.

7 Kuhlman R E, Stamp W G. Biochemical biopsy evaluation of the epiphyseal mechanism in a patient with vitamin D resistant rickets. J Lab Clin Med 1964; 64: 14-20.

8 Coleman R C, Becks H, Kohl F V N, Copp D H. Skeletal changes in severe phosphorous deficiency of the rat: tibia, metacarpal bone, costochondral junction, caudal vertebra. Arch Pathol 1950; 50: 209-32.

9 Engfeldt B, Zetterstrom R, Winberg J. Primary vitamin$D$ resistant rickets. III. Biophysical studies of skeletal tissue. J Bone Joint Surg (Am) 1956; 38: 1323-34.

Correspondence to Dr G J A I Snodgrass, Department of Paediatrics, London Hospital, Turner Street, London E1 1BB.

Received 2 October 1979 